\title{
Interação Universidade-Empresa
}

\author{
Ana Paula Cerrón* \\ José Gabriel Porcile Meirelles** \\ Luiz Alberto Esteves ${ }^{* * *}$
}

RESUMO - O trabalho discute a importância da cooperação Universidade-Empresa no Brasil e analisa os efeitos dessa cooperação no desempenho da firma. Existem diversos estudos que mostram que as universidades têm um importante papel na oferta de capacidades de pesquisa e de treinamento avançado em países em desenvolvimento. Nesses países em geral o peso do setor privado no esforço de $\mathrm{P} \& \mathrm{D}$ é menor. Estudos econométricos realizados com uma ampla base de dados para o Brasil mostram que a existência de cooperação entre empresas e universidades tem um impacto significativo no desempenho competitivo das firmas.

Palavras-chave: Cooperação universidade-empresa. Inovação tecnológica.

\section{INTRODUÇÃO}

A importância da cooperação universidade-empresa na elevação da produtividade e da competitividade das firmas aumentou enormemente na última década dado o contexto de acirrada competição internacional e de aceleração da mudança tecnológica nos mais diversos setores da economia. Neste trabalho apresentam-se algumas evidências sobre os efeitos dessa cooperação. O trabalho consta de duas seções, além da introdução e das conclusões. A primeira seção resume muito brevemente alguns aspectos teóricos de consenso na literatura internacional acerca da importância da relação universidade empresa na inovação. A segunda seção apresenta evidências microeconômicas, com destaque para a taxa de inovação e as vendas das firmas.

\footnotetext{
* Mestranda do Departamento de Economia da UFPR. Endereço eletrônico: anacerron@gmail.com

** PhD em Economic History, London School of Economics (1995). Atualmente é Professor Associado do Departamento de Economia da Universidade Federal do Paraná. Endereço eletrônico: porcile@ufpr.br .

***.Doutorando em Economia pela Università degli Studi di Siena. Atualmente é professor assistente I da Universidade Federal do Paraná. Endereço eletrônico: esteves@ufpr.br
} 


\section{RELAÇÃO UNIVERSIDADE-EMPRESA: UMA DIMENSÃO CHAVE DO PROCESSO DE INOVAÇÃO}

A maior parte dos economistas aceita que no longo prazo a taxa de crescimento de um país está estreitamente vinculada à sua capacidade de inovar e difundir tecnologia (Freeman, 1995; Lundvall, 1992; Nelson, 1993). Essa capacidade permite ampliar mercados (externos e internos), aumentar a competitividade com aumentos simultâneos do salário real e sustentar a expansão da demanda com estabilidade de preços. Não há consenso, no entanto, a respeito dos fatores que promovem a inovação e a difusão de tecnologia. O debate ainda permanece aberto nesse aspecto. Mas já é possível identificar algumas regularidades empíricas ou fatos estilizados, amplamente documentados na literatura, que podem contribuir na identificação de tais fatores (Albuquerque, 1996 e 2004; Albuquerque et al, 2005; Cerrón, 2007; Rapini, 2004; Rapini e Righs, 2005 e 2006).

Principais fatos estilizados são os seguintes:

i) $\mathrm{O}$ aprendizado tecnológico não é um processo linear que se inicia nos laboratórios e nas pesquisas científicas até chegar à empresa. Pelo contrário, a inovação e difusão de tecnologia surgem da interação entre agentes heterogêneos, públicos e privados, cujos objetivos e formas organizacionais são diversos;

ii) Nessa interação, a própria difusão de tecnologia ocorre paralelamente com a geração de adaptações e de inovações incrementais, estimuladas por problemas específicos de cada mercado. Não é um processo passivo de cópia, mas um processo ativo de aprendizado que exige esforços e investimentos em catching-up;

iii) $\mathrm{O}$ sucesso da interação entre agentes heterogêneos (e o sucesso do próprio processo de inovação e difusão de tecnologia) depende em grande medida do arcabouço institucional desenhado para coordenar e compatibilizar diversos objetivos, processos e regras. O aprendizado tecnológico será mais intenso quando o marco institucional permitir que as decisões de investimento em tecnologia se complementem e se fortaleçam mutuamente.

Quais são os agentes heterogêneos que interagem na inovação e difusão de tecnologia?

Em primeiro lugar cabe um papel central às firmas, cuja sobrevivência e expansão dependem, em muitos setores, da inovação tecnológica. São elas, por definição, as que estão obrigadas a auscultar as demandas do mercado e a responder, através da inovação, à 
concorrência interna e externa. Essas firmas mantêm fortes relações como fornecedoras de equipamentos ou de insumos que em muitos casos são também uma das principais fontes do progresso técnico. Há um fluxo intersetorial de inovações que ajuda a compreender a dinâmica tecnológica da estrutura produtiva.

Por outro lado, existem agentes públicos e privados especializados em atividades de pesquisa científica e tecnológica que não respondem diretamente aos incentivos do mercado. Esses agentes respondem a estímulos que em parte são originados no âmbito puramente científico e tecnológico (os paradigmas científico e tecnológico) e em parte são originados no mundo econômico. Por suas características, representam o loci de esforços em P\&D em áreas em que há falhas de mercado, como tem sido discutido (entre outras) pela teoria dos bens públicos e da informação imperfeita. Alguns exemplos desse tipo de esforços em P\&D são as seguintes:

i) Certas atividades científicas são importantes para a inovação, mas como elas estão muito afastadas do uso prático imediato, a viabilidade de seu financiamento depende do concurso de agentes públicos ou de parcerias público-privadas que reduzem a incerteza e o custo do investimento;

ii) Em outros casos, as firmas não têm como impedir que os conhecimentos que elas produzem (via investimentos em $\mathrm{P} \& \mathrm{D}$ ) se difundam sem grandes custos adicionais para outros agentes. Como no caso da engenharia reversa. Ela permite copiar certa inovação, que passa então a ser usada por outros agentes, se não estiver protegida por patentes ou por conhecimentos tácitos produzidos através da experiência. $\mathrm{Na}$ agricultura, é muito freqüente que a imitação ocorra de forma relativamente rápida a partir da simples observação das técnicas usadas em estabelecimentos mais avançados. Em ambos os casos a inovação na firma pode acabar beneficiando os seus concorrentes. Isso coloca o clássico problema do "carona" e do investimento subótimo em tecnologia, na medida em que a mesma adota a forma de um bem público imperfeito.

As universidades surgem como atores chaves do processo de inovação e de difusão de tecnologia no âmbito da interação entre agentes heterogêneos (Cohen et al, 2002; Mowery e Sampat, 2005). A seguir, apresentam-se evidências microeconômicas que revelam claramente o papel chave da interação universidade-empresa no desempenho das firmas. 


\section{RELAÇÃO UNIVERSIDADE-EMPRESA E DESEMPENHO DA FIRMA}

Um tema chave é mensurar o impacto da interação universidade-empresa sobre o desempenho da firma. A hipótese chave é que uma maior interação universidade-empresa melhora a capacidade de inovação das firmas e isso se reflete nas vendas. A seguir se mostram os resultados obtidos a partir de informações do Banco Mundial sobre ambiente de negócios no Brasil (World Bank Investment Climate, Brasil, 2003). As informações foram colhidas com base na entrevistas de 1640 empresas brasileiras e submetidas a diversos testes econométricos: modelos probit para determinar o efeito de certas variáveis sobre a probabilidade de inovar e modelos OLS de regressão para estimar taxas de crescimento das vendas das firmas. Os principais resultados são apresentados na seqüência:

i) Observou-se que $65 \%$ das firmas entrevistadas inovaram em processo e $65 \%$ em produto;

ii) O tamanho médio das empresas da amostra é de 80 empregados, enquanto que o tamanho das que treinam seus funcionários na universidade é de 316, e das que cooperam com as universidades na inovação é de 525;

iii) Apenas $7 \%$ das empresas treinam seus funcionários na universidade e somente $1.7 \%$ cooperam com a universidade na inovação;

iv) As empresas que cooperam com a universidade na inovação gastam menos em inovação que as que não cooperam ( $\mathrm{R} \$ 803$ por trabalhador por ano frente a $\mathrm{R} \$ 878$ por trabalhador por ano, em preços de 2002);

v) As empresas que cooperam com a universidade têm uma probabilidade de inovar sete pontos acima das que não cooperam (por exemplo, a probabilidade de inovar aumenta de 20 para $27 \%$ );

vi) $O$ treinamento do pessoal das firmas nas universidades aumenta em três pontos a probabilidade de obter uma inovação de processo, mas não afeta a probabilidade de obter uma inovação de produto;

vii) A inovação de produto aumenta em seis pontos percentuais o crescimento das vendas das firmas;

viii) Empresas que inovam simultaneamente em processo e produto podem ter aumentos de até 10 pontos percentuais no crescimento das vendas quando comparadas com as firmas não inovadoras; 
ix) Independentemente de seus efeitos sobre a inovação, o treinamento de empregados na universidade pode aumentar as vendas da firma em até treze pontos percentuais.

As evidências anteriores sugerem que há de fato um forte impacto da cooperação sobre o desempenho das firmas, tanto direta como indiretamente (estimulando a inovação). Mais ainda, há evidencias de um melhor desempenho a partir de custos menores.

\section{CONCLUSÕES}

A literatura sugere que uma estreita cooperação entre universidade e empresas é uma dimensão importante na construção de um sistema de inovação eficiente. Esta simbiose entre o âmbito acadêmico com o empresarial é visível nas economias desenvolvidas, sendo ainda mais importante no caso das economias em desenvolvimento. Isso se deve ao fato de que neste último tipo de economias as capacidades tecnológicas e de pesquisa encontram-se fortemente concentradas nas universidades, particularmente nas universidades públicas. Torna-se necessário construir pontes entre esses dois âmbitos. Pesquisas realizadas no nível microeconômico apontam para uma influência claramente positiva e significativa da cooperação universidade empresa sobre a probabilidade de inovação da firma. Ao mesmo tempo, as informações mostram que a inovação tem efeitos (também positivos e significativos) sobre o desempenho da firma.

\section{REFERÊNCIAS}

ALBUQUERQUE, E. M. Sistema Nacional de Inovação no Brasil: uma análise introdutória a partir de dados disponíveis sobre Ciência e Tecnologia. Revista de Economia Política. São Paulo, v.16, n.3, p. 438-498, 1996.

ALBUQUERQUE, E. Science and technology systems in Less Developed countries: identifying a threshold level and focusing in the cases of India and Brazil. In: MOED, H.; GLÄNZEL, W.; SCHMOCH, U. (eds) Handbook of quantitative science and technology research: the use of publication and patent statistics in studies of S\&T systems. Dordrecht: Kluwer Academic Publishers, 2004.

ALBUQUERQUE, E.; SILVA, L.; PÓVOA, L. Diferenciação inter-setorial na interação entre empresas e universidades no Brasil. São Paulo em Perspectiva. São Paulo, v. 19, n. 1, p. 95-104, 2005.

CERRÓN, A.P. (2007) “Cooperação universidade-empresa no Paraná: um

diagnóstico", seminário sobre interação universidade - empresa, Campinas, Janeiro 2007. 
COHEN, W.; NELSON, R.; WALSH, J. Links and impacts: the influence of public R\&D on industrial research. Management Science. v. 48, n. 1, p. 1-23, 2002.

FREEMAN, C. The "National System of Innovation" in historical perspective. Cambridge Journal of Economics. v. 19, n. 1, 1995.

LUNDVALL, B. National Systems of Innovation: Toward a Theory of Innovation and Interactive Learning. London: Pinter, 1992.

MOWERY, D.; SAMPAT, B. (2005) Universities in National Innovation Systems. In: FAGERBERG, J.; MOWERY, D.; NELSON, R. (2005) The Oxford Handbook of Innovation. Oxford: Oxford University Press.

NELSON, R. R. National Innovation Systems: a comparative analysis. New York: Oxford University Press, 1993.

RAPINI, M. (2004). Interação universidade-indústria no Brasil: uma análise exploratória a partir do diretório de grupos de pesquisa do CNPq. Dissertação de Mestrado. Rio de Janeiro: IE/UFRJ.

RAPINI, M.; RIGHI, H. (2005) Interação universidade-empresa no Brasil em 2002 E 2004: uma aproximação a partir dos grupos de pesquisa do CNPq. Congresso $A N P E C$, Natal.

RAPINI, M.; RIGHI, H. (2006) O diretório dos grupos de pesquisa do CNPq e a interação universidade-empresa no Brasil em 2004. Revista Brasileira de Inovação, 5 (1): 131156. 